\title{
Simulation Study to Evaluate the Impact of Fracture Parameters on Shale Gas Productivity
}

\author{
Abdul Majeed Shar ${ }^{1}$, Waheed Ali Abroª, Aftab Ahmed Mahesar ${ }^{3}$, Kun Sang Lee ${ }^{2 b}$ \\ RECEIVED ON 10.01.2019, ACCEPTED ON 19.02.2019
}

\begin{abstract}
The production from shale gas reservoirs has significantly increased due to technological advancements. The shale gas reservoirs are very heterogeneous and the heterogeneity has a significant effect on the quality and productivity of reservoirs. Hence, it is essential to study the behavior of such reservoirs for accurate modelling and performance prediction. To evaluate the impact of fracture parameters on shale gas reservoir productivity using CMG (Computer Modelling Group) stars simulation software was the main objective of this study. In this paper, a comprehensive analysis considering an example shale gas reservoir was conducted for production performance analysis considering uniform and non-uniform fractures configurations. Several simulations were performed by considering the multi-stage hydraulically fractured reservoir. The sensitivities conducted includes the different cases of moderate and severe heterogeneity along with variable fractures half-length, effect of changing fracture spacing, variable fracture conductivities. The simulation results showed that by increasing conductivity of fracture increases the gas production rate significantly. Moreover, cases of reservoir permeability heterogeneity were analyzed which show the significant effect on gas rate and on cumulative gas production. The results of this study can be used to improve the effectiveness in designing and developing of shale gas reservoirs and also to improve the accuracy of analyzing heterogeneous shale gas reservoir performance.
\end{abstract}

Key Words: Unconventional Resources, Shale Gas, Hydraulic Fractures, Non-Uniform Fractures, Heterogeneity, Production Performance

\section{INTRODUCTION}

Unconventional oil and gas reservoirs have become increasingly important sources of energy in balancing the supply and demand gap for the world [1]. Among all unconventional reservoirs, shale gas resources have a huge potential in the world [2]. Shale gas resources sustainable developments is complex due to two key issues (i) extremely low permeability and poor porosity (ii) free and adsorbed gas resides together in the reservoirs, hence the production mechanism will be very complex [3]. However, advancements in technology in drilling of horizontal wells and hydraulically fracturing reservoirs have been regarded as possible methods to improve the gas production significantly from shale gas reservoirs [4]. In order, to

${ }^{1}$ Petroleum Engineering Department, NED University of Engineering and Technology, Karachi, Pakistan.

Email: majeed99pg@gmail.com (Corresponding Author)

${ }^{2}$ Department of Resources and Environmental Engineering, Hanyang University, Seoul, South Korea. Email: ${ }^{a}$ engineerwaheedali@gmail.com, bkunslee@ hanyang.ac.kr

${ }^{3}$ Institute of Petroleum and Natural Gas Engineering, Mehran University of Engineering and Technology, Jamshoro, Pakistan. Email: engr.aftabmahesar@gmail.com

This is an open access article published by Mehran University of Engineering and Technology, Jamshoro under CC BY 4.0 International License. 
understand the production behavior and to develop such extremely low permeability reservoirs requires accurate modelling prior to drilling and execution of fracturing jobs. Modelling such reservoirs are very complicated due to number of reasons; such as growth of the hydraulic fracture, poor understanding of fracturing process and parameters and scarcity of quality data for reservoir [5]. Hence, it is very challenging to analyze the performance of shale gas reservoirs, due to the complex geometry of fractures and design of fracture treatment [6]. The success of any of the tight permeability reservoirs depends upon the effectiveness of hydraulic fracturing job [4]. For fracture job effectiveness reservoir simulation models development is essential prior to the execution of operations on real reservoirs in order to simulate the reservoir behavior accurately. This could be performed by creating complex non-uniform fracture geometry in simulation model. Fractures control the productivity of shale gas behaviors and their handling in simulation is appropriately is essential [5]. Several different models have been suggested by the researchers for modelling of the fracture-matrix behavior in tight porous media [7-9]. These numerical simulations performed consists of (i) EC (Equivalent Continuum Model) [10-11]; (ii) DPSP (Dual Porosity Model Single Permeability Model) [12-13] (iii) DPDP (Dual Porosity Dual Permeability Model) [13] (iv) MINC (Multiple Interaction Continua Model) [14]. (V) DFN (Discrete Fracture Network Model) [15] (VI) Multiple porosity model [16]. Modelling the reservoir behavior using equivalent continuum model, the properties of the all fracture elements are kept average for the whole system and is not as effective as compared to others models due to the difficulty in obtaining the average properties of the porous media [5]. For effective continuum model construction [17] modelled shale gas reservoir behavior by taking account of multi-component gas adsorption. Modelling the reservoir behavior considering dual porosity model number of researcher has published a lot $[8,12]$. DPSP and DPDP based on their matrix and fracture properties [18]. In this modelling approach, there is interaction of fluid $\mathrm{s}$ transfer between matrix and fractures and wellbore. The most common and more accurate method of modelling considered in the industry is the DPSP and DPDP [19] modelled the shale gas reservoir behavior using the experimental and field data as an input to simulate the reservoir performance by constructing the dual porosity 2D model. For more accurate modelling and characterization of low permeability reservoirs behavior a method of MINC (Multiple Interaction Continuum Media) was introduced by [14]. MINC method provides better numerical approximation and calculates the interblock fluid flow more accurately. The present study focus is solely based on the shale gas reservoir production performance analysis under non-uniform hydraulic fractures. This was analyzed considering different configurations of fracture parameters such as fracture geometry, fracture conductivity, fracture half-length and fracture spacing.

\subsection{Numerical Simulation Model}

In this paper a simulation model of an example reservoir using GEM compositional simulator was developed. The model developed has dimensions of $2550 \mathrm{ft}$. length $2550 \mathrm{ft}$ width and $250 \mathrm{ft}$. in height and are 50x50x10 grid cells in $\mathrm{x}, \mathrm{y}$ and $\mathrm{z}$ direction. The reservoir contains the natural fractures in the entire reservoir in every $40 \mathrm{ft}$. and in addition to naturally fractured reservoir, the model developed also was hydraulically fractured. For results reliability of any constructed model validity is essential parameter. Hence, for verification of the model accuracy prior to sensitivity analysis and long period production forecast, a model of shale gas reservoir numerical simulation model containing natural and hydraulic fractures was constructed and validated with field data in order to ensure the reliability of the results. Further, to sensitivity analysis comparison was done with the field data taken from Barnet shale original data published by Grieser et. al. [20], that data is present within the public domain. The shale gas model developed reflects the production of single phase gas from isotropic formation. A horizontal well was designed to penetrate the reservoirs all the way to the centre of reservoir and produce the gas at a rate of 2 MMscf/day. The minimum bottom hole pressure was designed have a limit of $550 \mathrm{psi}$. The key petrophysical properties of reservoir and rock are listed in Table 1. The reservoir had an initial pressure of 3000 psi. A number of simulations were performed for sensitivity analysis (Table 2). The effect on production behavior of shale gas reservoirs was analyzed, considering three different categories of parameters: the reservoir parameters, reservoir heterogeneity and hydraulic fracture parameters. For reservoir parameters only one sensitivity parameter was considered, which includes the matrix permeability. However, for impact of 
fracture parameters on shale gas production performance, the sensitivities run include the fracture half-length, fracture spacing and fracture conductivity.

\begin{tabular}{|c|c|}
\hline \multicolumn{2}{|c|}{$\begin{array}{c}\text { TABLE 1. PARAMETERS USED FOR } \\
\text { SYNTHETIC 3D MODEL FOR SHALE GAS } \\
\text { RESERVOIR PERFORMANCE ANALYSIS }\end{array}$} \\
\hline Parameters & Synthetic Model Values \\
\hline Reservoir pressure & 3000 (psi) \\
\hline Porosity Matrix & 0.025 (fraction) \\
\hline Porosity Fracture & 0.0012 (fraction) \\
\hline $\begin{array}{c}\text { Permeability of } \\
\text { Matrix }\end{array}$ & $0.00001(\mathrm{md})$ \\
\hline $\begin{array}{l}\text { Permeability of } \\
\text { Fracture }\end{array}$ & $0.02(\mathrm{md})$ \\
\hline $\begin{array}{c}\text { Natural fractures } \\
\text { spacing }\end{array}$ & $40(\mathrm{ft})$ \\
\hline Rock compressibility & $1.00 \mathrm{E}-06(1 / \mathrm{psi})$ \\
\hline Langmuir pressure & 550 (Psi) \\
\hline $\begin{array}{l}\text { Maximum adsorption } \\
\text { volume }\end{array}$ & $167(\mathrm{scf} / \mathrm{t})$ \\
\hline $\begin{array}{l}\text { Horizontal well } \\
\text { length }\end{array}$ & $1275(\mathrm{ft})$ \\
\hline $\begin{array}{c}\text { Radius of the } \\
\text { wellbore }\end{array}$ & $0.325(\mathrm{ft})$ \\
\hline $\begin{array}{l}\text { Production period for } \\
\text { simulation run }\end{array}$ & 25 (year) \\
\hline Fracture half-length & $350(\mathrm{ft})$ \\
\hline Fracture spacing & $250(\mathrm{ft})$ \\
\hline Fracture height & $100(\mathrm{ft})$ \\
\hline Fracture width & $0.0005(\mathrm{ft})$ \\
\hline Fracture permeability & $10000(\mathrm{md})$ \\
\hline $\begin{array}{c}\text { Flowing bottomhole } \\
\text { pressure }\end{array}$ & $550(\mathrm{psi})$ \\
\hline
\end{tabular}

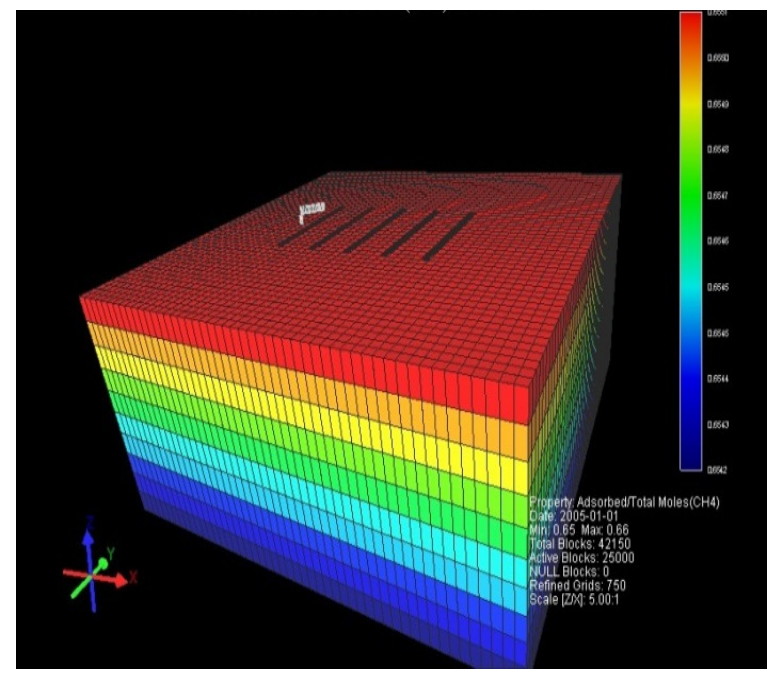

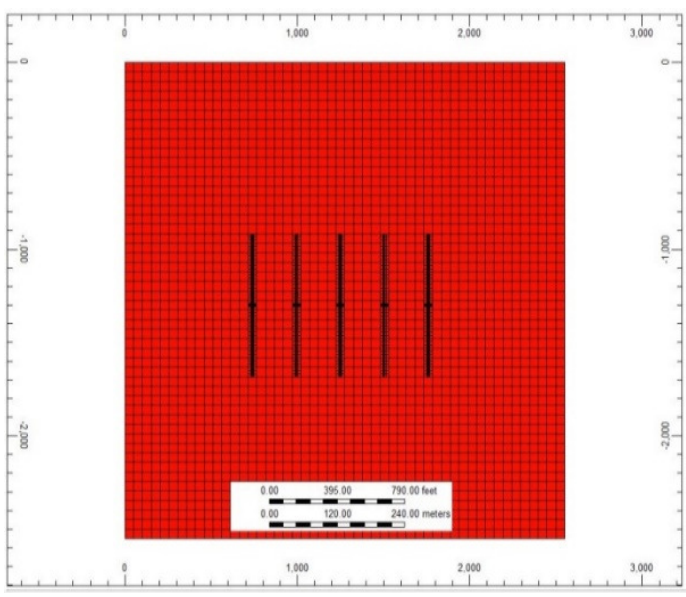
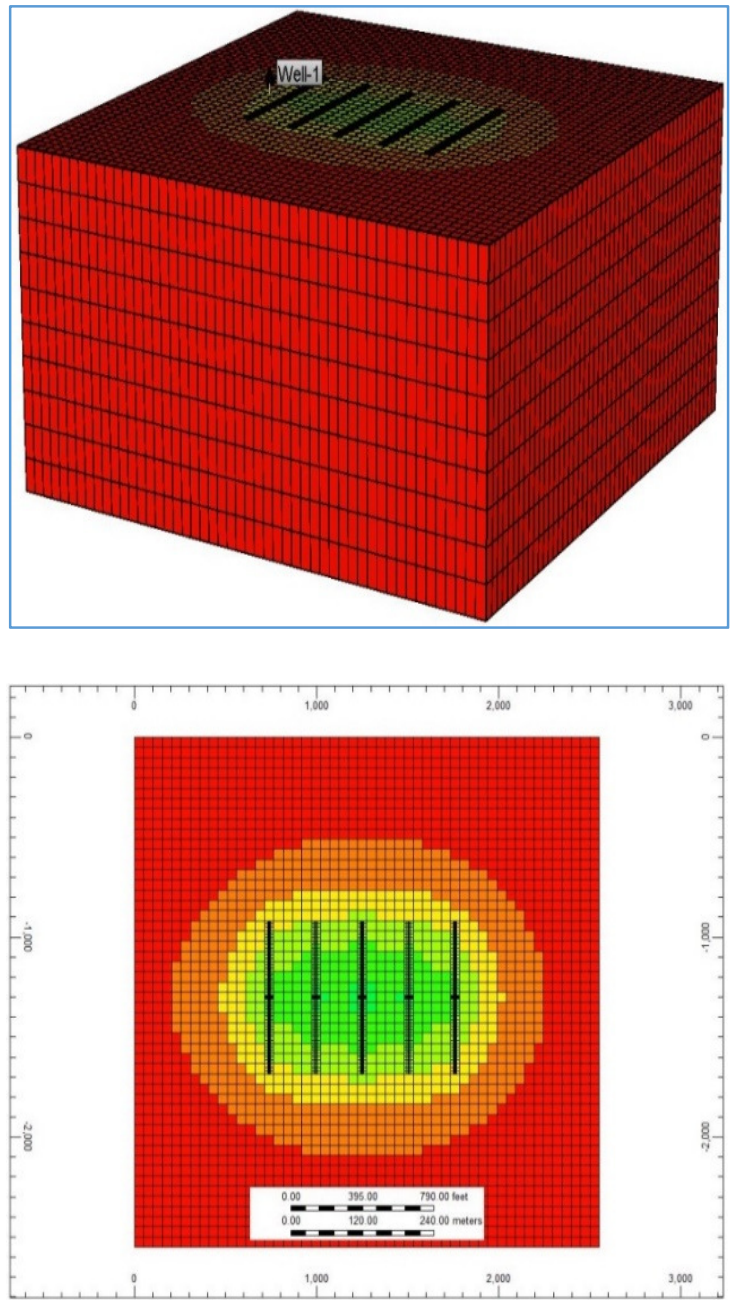

FIG. 1. A MULTIPLE HYDRAULIC FRACTURE SIMULATION MODEL (3D AND 2D VIEW) WITH LOGARITHMICAL GRID REFINEMENTS DEVELOPED USING GEM CMG SOFTWARE. IN ILLUSTRATION, THE UPWARD SHOWS THE MODEL AT INITIAL CONDITIONS AND DOWN IS PRODUCTION CONDITIONS. 


\begin{tabular}{|c|c|c|c|c|c|}
\hline \multicolumn{6}{|c|}{$\begin{array}{l}\text { TABLE 2. THE KEY PARAMETERS USED TO MODEL THE EXAMPLE RESERVOIR AND THEIR } \\
\text { RANGES FOR SENSITIVITY ANALYSIS UNDER DIFFERENT CONDITIONS }\end{array}$} \\
\hline Case & $\begin{array}{c}\text { Reservoir and } \\
\text { Fracture Sensitivity } \\
\text { Parameter }\end{array}$ & $\begin{array}{l}\text { Half-Length } \\
\text { (ft) (Range) }\end{array}$ & $\begin{array}{l}\text { Fracture Spacing } \\
\quad(\mathrm{ft}) \text { (Range) }\end{array}$ & $\begin{array}{c}\text { Fracture } \\
\text { Conductivity } \\
(\mathrm{mD}-\mathrm{ft})(\text { Range })\end{array}$ & $\begin{array}{c}\text { Cumulative } \\
\text { Gas } \\
\text { Produced } \\
\text { (MMscf) } \\
\text { (Range) }\end{array}$ \\
\hline Base & $\begin{array}{l}\text { Uniform width and } \\
\text { length of fracture }\end{array}$ & 350 & 250 & 12 & 7660 \\
\hline Case-1 & $\begin{array}{l}\text { Effect of multiple } \\
\text { fractures with } \\
\text { variable half-length }\end{array}$ & $\begin{array}{c}(1 \mathrm{a}) \\
350,300,200,100,50 \\
\text { (1b) } 350,270 \\
100,300,200\end{array}$ & 250 & 12 & $\begin{array}{l}\text { (1a) } 7334 \\
\text { (1b) } 7484\end{array}$ \\
\hline Case-2 & $\begin{array}{l}\text { Effect of fractures } \\
\text { spacing }\end{array}$ & $\begin{array}{l}\text { Uniform half-length } \\
\qquad 350\end{array}$ & $\begin{array}{c}(2 a) \\
100,150,350,400 \\
(2 b) \\
100,400,400,100\end{array}$ & 12 & $\begin{array}{l}\text { (2a) } 7770 \\
\text { (2b) } 7864\end{array}$ \\
\hline Case-3 & $\begin{array}{l}\text { Effect of variable } \\
\text { fracture } \\
\text { conductivity }\end{array}$ & 350 & 250 & $\begin{array}{l}\text { (3a) } 20 \\
\text { (3b) } 5\end{array}$ & $\begin{array}{l}\text { (3a) } 8355 \\
\text { (3b) } 5961\end{array}$ \\
\hline Case-4 & $\begin{array}{l}\text { Effect of } \\
\text { permeability } \\
\text { heterogeneity }\end{array}$ & 350 & 250 & 12 & $\begin{array}{l}(4 a) 7315 \\
(4 b) 5628\end{array}$ \\
\hline
\end{tabular}

\subsection{Results and Analysis}

The effect on production behavior of shale gas reservoirs was analyzed, considering three different categories of parameters: the reservoir parameters, reservoir heterogeneity and hydraulic fracture parameters. For reservoir parameters only one sensitivity parameter was considered, which includes the matrix permeability. However, for impact of fracture parameters on shale gas production performance the sensitivity run include the fracture half-length, fracture spacing and fracture conductivity.

\subsubsection{Effect of Variable Fracture Half-Length}

Fracture half-length is the main parameter that affects the productivity of low permeability shale gas reservoir due to their high conducive flow channels providing enough space for fluids to flow towards the wellbore. In this study sensitivity was conducted for two cases including (Case-1a) the fracture half-length decreasing in descending order with values of fracture half-length as $350,300,200,100$, and $50 \mathrm{ft}$. (Case-1b) random order length change with values of half-length $350,270,100,300$, and $200 \mathrm{ft}$. The dynamic pressure response at different periods of time for the model is shown in Fig. 2(a-c). However, the effect of changing fracture half-length on gas production cumulative and gas rate is shown in Fig. 3(a-b). Fig. 3 shows that the base case has larger fracture half-length compared to Case-1a and Case- $1 \mathrm{~b}$; hence the rate of production is higher than other two cases. This is due to the larger area of flow for the fluid with high permeability channels hydraulic fractures. It has been reported by many authors that the larger the length of fracture the larger will be the stimulated reservoir volume leading to more contribution towards gas cumulative production and gas production rate from such reservoirs. The cumulative gas production of base case is 7660 MMscf. The cumulative production of gas reduced when fracture half-length decreased to $4.3 \%$ for Case-1a and the production cumulative decreased up to $2.3 \%$ for Case-1b lower than the base case cumulative production. Similar observations have been also reported by the other authors (Cipola et. al. [20]). 


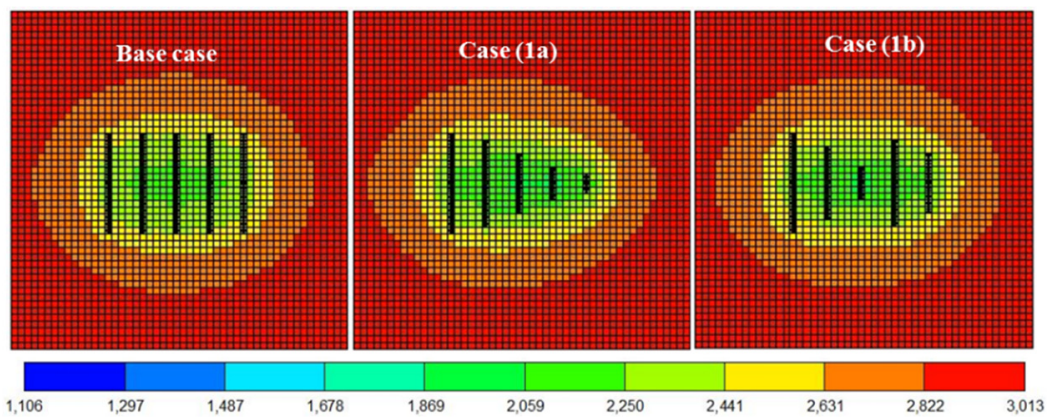

(a) 1 year

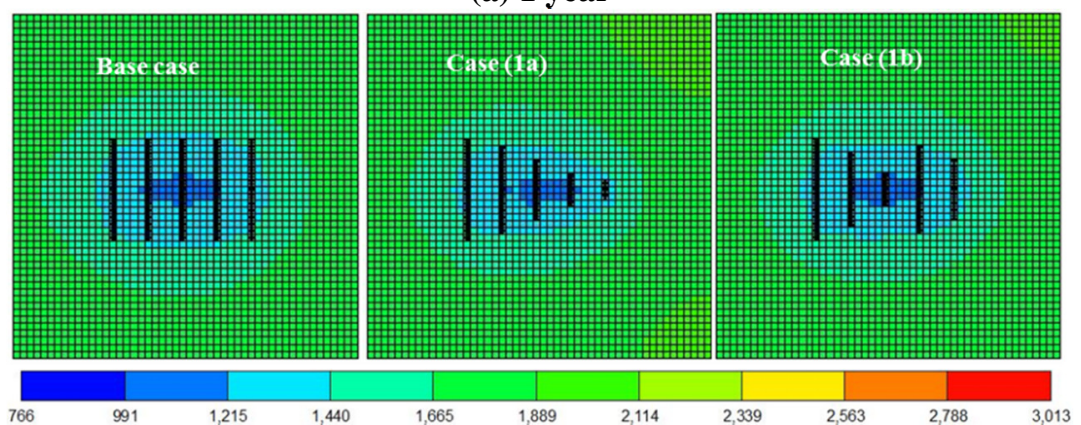

(b) 10 years

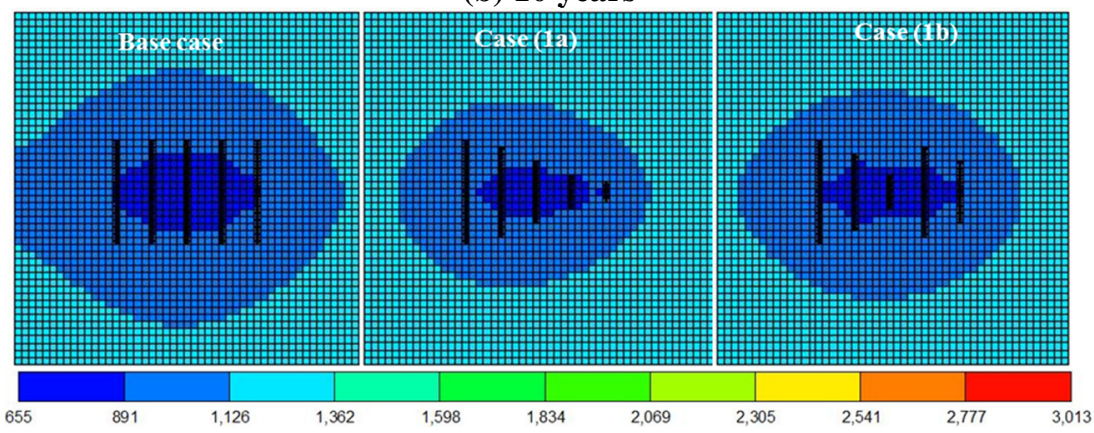

(c) 25 years

FIG. 2. COMPARISON OF PRESSURES AT DRAINAGE BOUNDARY AT DIFFERENT TIME PERIODS

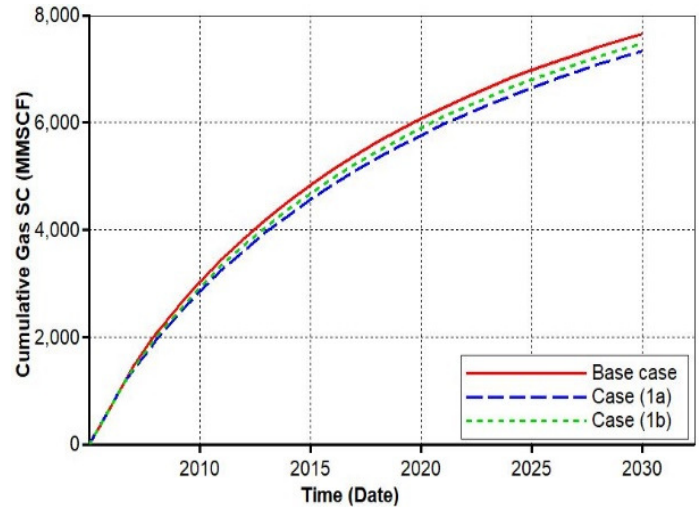

(a) Cumulative Gas Production

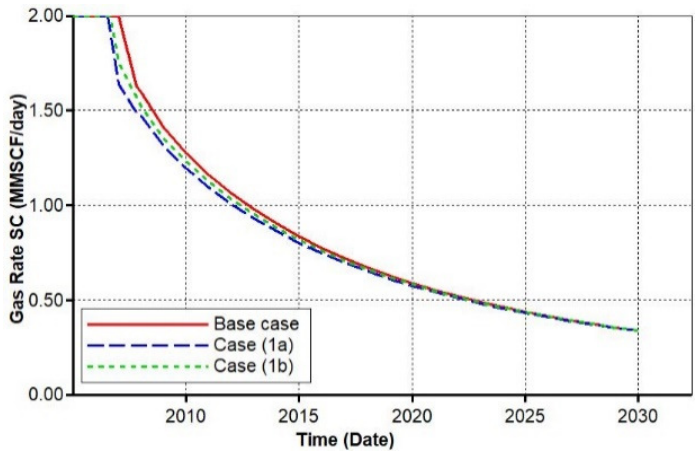

(b) The Gas Rate From Shale Gas Reservoir Production

FIG. 3. INFLUENCE OF THE FRACTURE HALF-LENG 


\subsubsection{Effect of Fractures Spacing}

It is important to consider the fracture spacing effect on gas production rate when there are several different fractures within the reservoir. It is obvious that if the number of fractures increased more capital will be needed to invest. Many researchers have provided with different solutions and impact of various parameters either by conducting experiments and by modelling the shale gas reservoir behaviors [23-30], the Cipola et. al. [21-22] and Guo et. al. [5] have also proposed that for shale gas reservoirs development under economical rates it is essential to reduces the number of fractures [5]. However, if the fractures number is minimized then the rate of fluid transfer from fractures to matrix subsequently to wellbore will be affected and is not good for gas production from shale gas reservoirs. If the numbers of fractures are increased, then more capital will be required to invest and return on investment may take longer. Therefore, the fracture spacing effect must be evaluated for production performance of shale gas reservoirs. Due to this, present study conducted sensitivity analysis on fracture spacing. This study analyzed and compared the effect of fracture spacing considering total five fractures. Simulation was run for long period of time to assess the impact of varying fracture spacing on production of shale gas reservoirs. The effect of fracture spacing was assesses by designed two different cases, asymmetrical with fracture spacing of 100-150-350-400 ft and symmetrical with fracture spacing of 100, 400, 400, and $100 \mathrm{ft}$., for five fractures have equal width. All other properties were kept similar as those of base case. The effect of fracture spacing on cumulative gas production and gas rate is shown in Figs. 4(a-b)-5(a-c), which shows that the effect of fracture spacing on rate of gas production for shale gas reservoir is small. The difference exists at only early production periods but the effects are less significant at the late production periods. We compared different cases of simulation results and found that Case-2b has higher cumulative gas production than Case-2a and base case due to symmetrical fracture spacing. Quantitatively, Case- $2 \mathrm{~b}$ is $2.7 \%$ higher and Case-2a is $1.4 \%$ higher than base case in cumulative gas production.

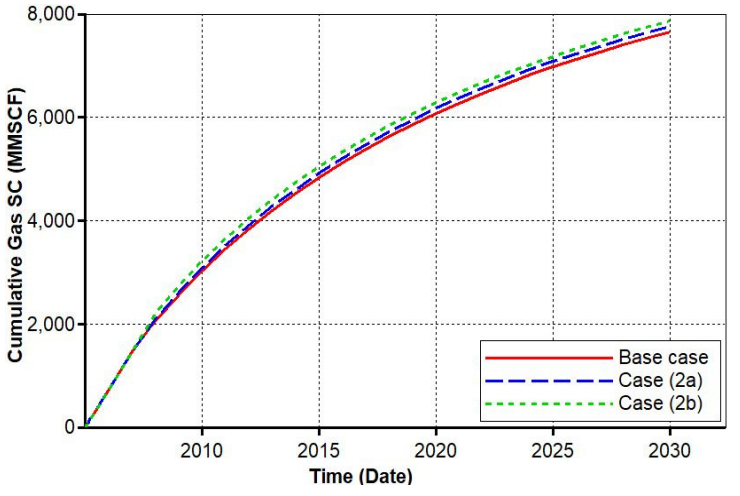

(A) CUMULATIVE GAS PRODUCTION

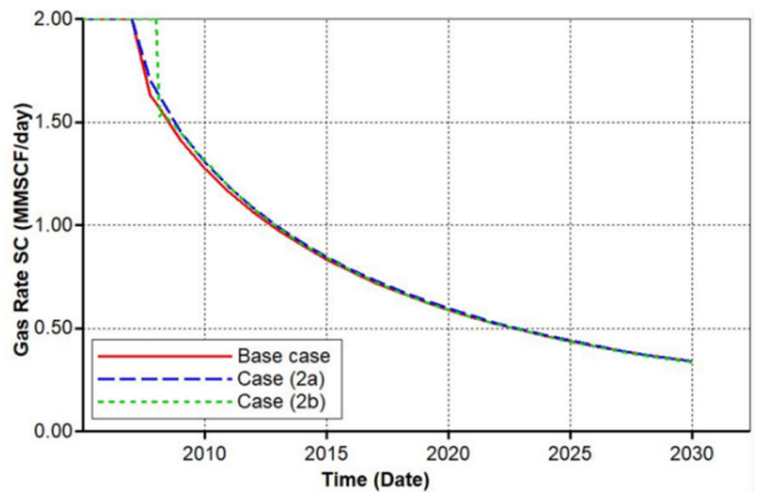

(B) GAS RATE OF SHALE GAS RESERVOIR

FIG.E 4. EFFECT OF FRACTURE SPACING

\subsubsection{Effect of Fracture Conductivity}

The conductivity of fracture is mainly affected by the permeability and width of the fracture, hence for this study the values of fracture conductivity were selected based on actual range reported. According to the data published on shale gas reservoirs in the US, the permeability varies and is in range of micro to nanodarcy. Sensitivity conducted by considering the two different fracture conductivity cases (Case-3a) and (Case-3b) along with base case. The fracture conductivity of Case-3a has value of $20 \mathrm{mD}-\mathrm{ft}$ and Case- $3 b$ was assigned with fracture conductivity value of $5 \mathrm{mD}$-ft. all other parameters of the model were kept similar. The effect of varying fracture conductivities on gas production rate and cumulative gas production from shale gas reservoir model is illustrated in Fig. 6. Fig. 6 show that the difference in gas production rate and cumulative gas production among base case and

Mehran University Research Journal of Engineering and Technology, Vol. 39, No. 2, April 2020 [p-ISSN: 0254-7821, e-ISSN: 2413-7219] 

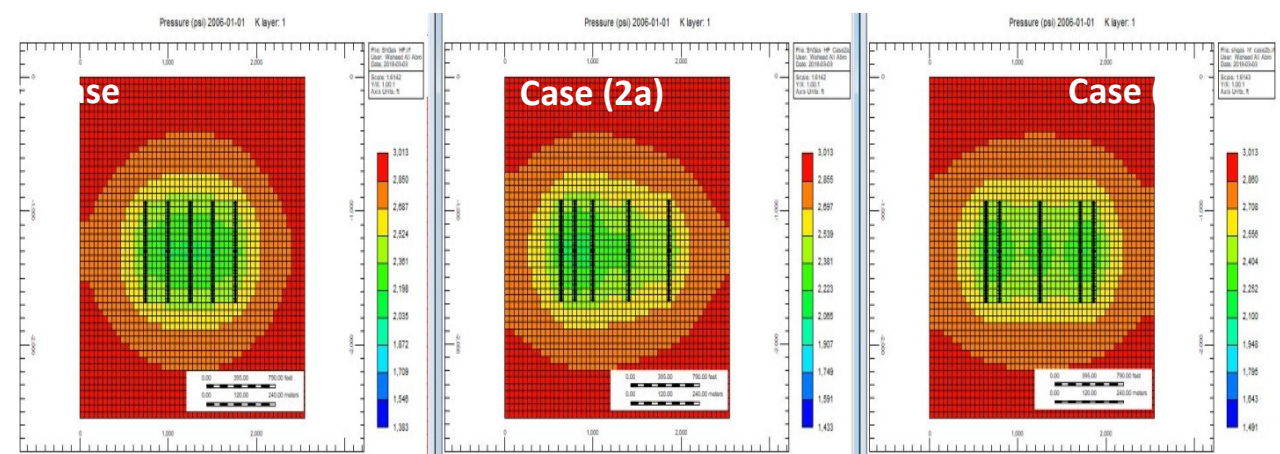

(a) 1 year
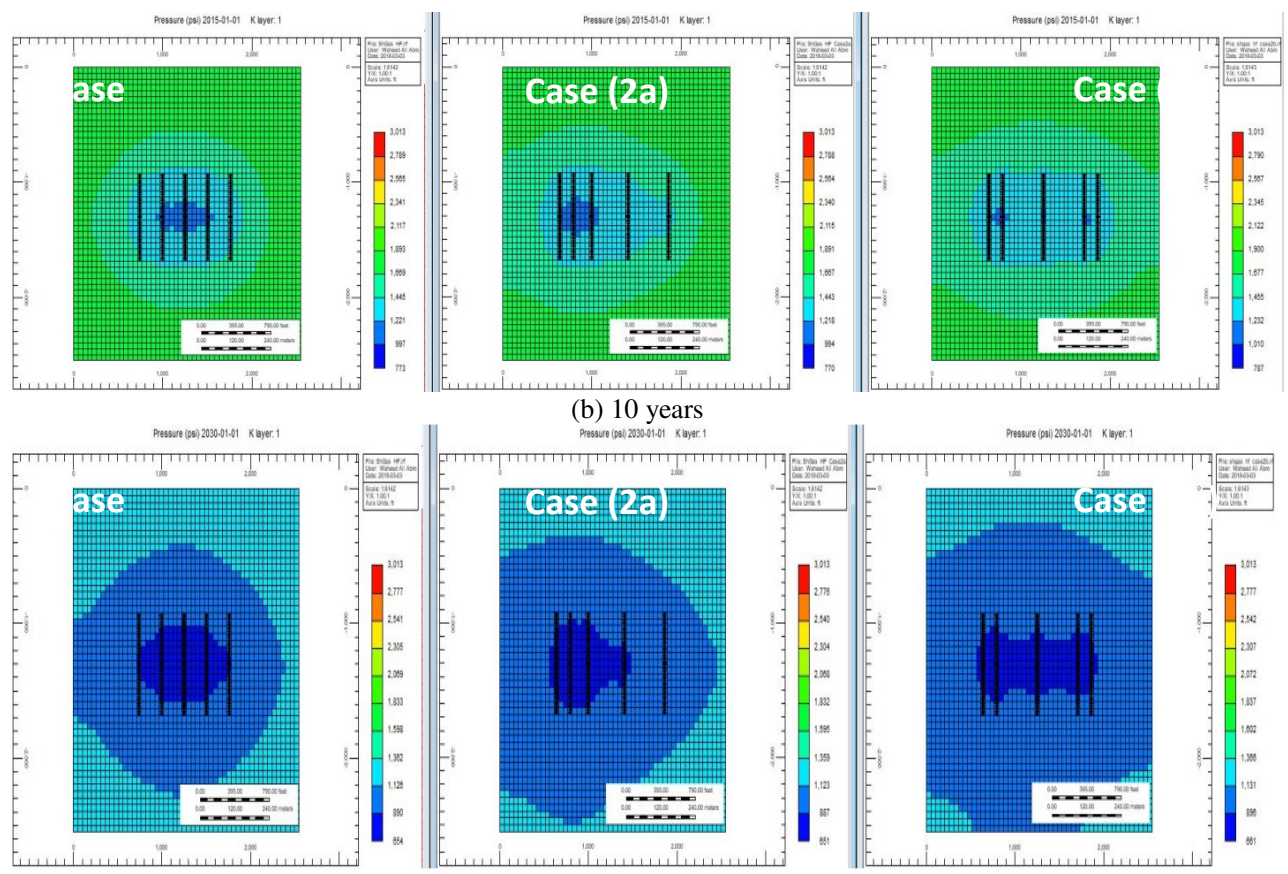

(c) 25 years

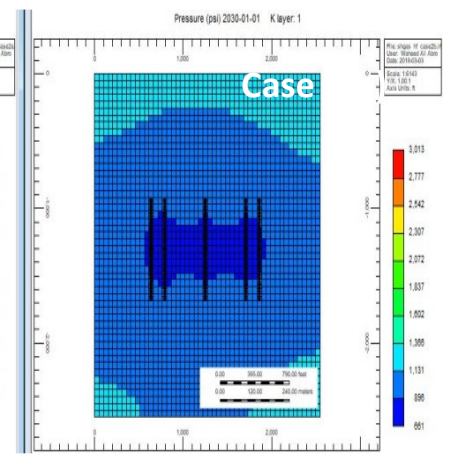

FIG. 5 COMPARISON OF PRESSURES AT DRAINAGE BOUNDARY AT DIFFERENT TIME PERIODS
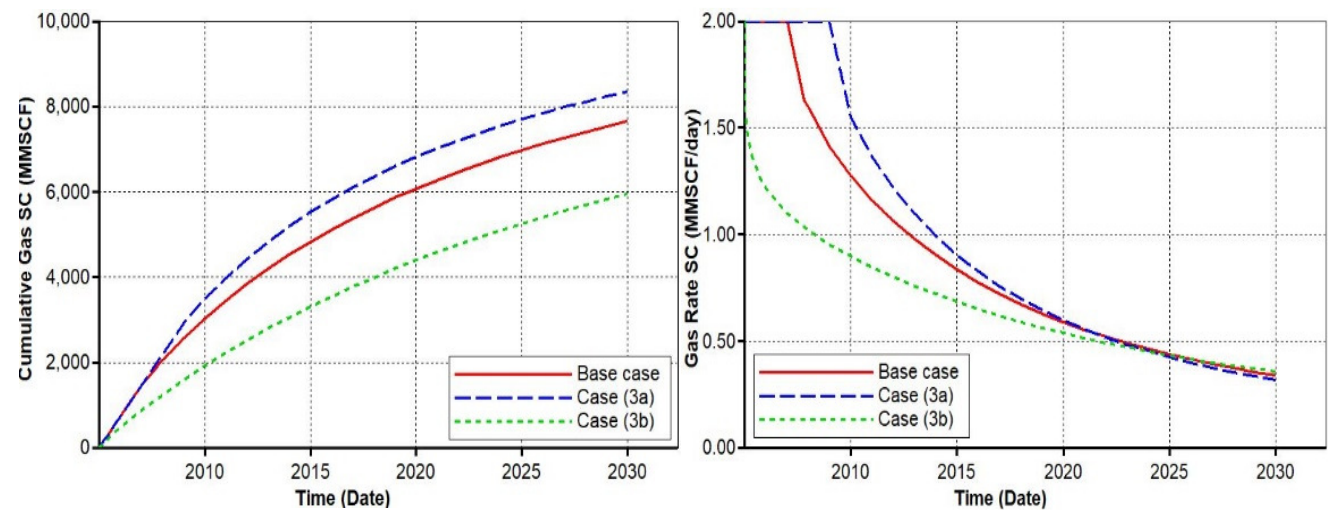

FIG. 6. EFFECT OF FRACTURE CONDUCTIVITY ON CUMULATIVE GAS PRODUCTION AND GAS RATE ON SHALE GAS PRODUCTION 


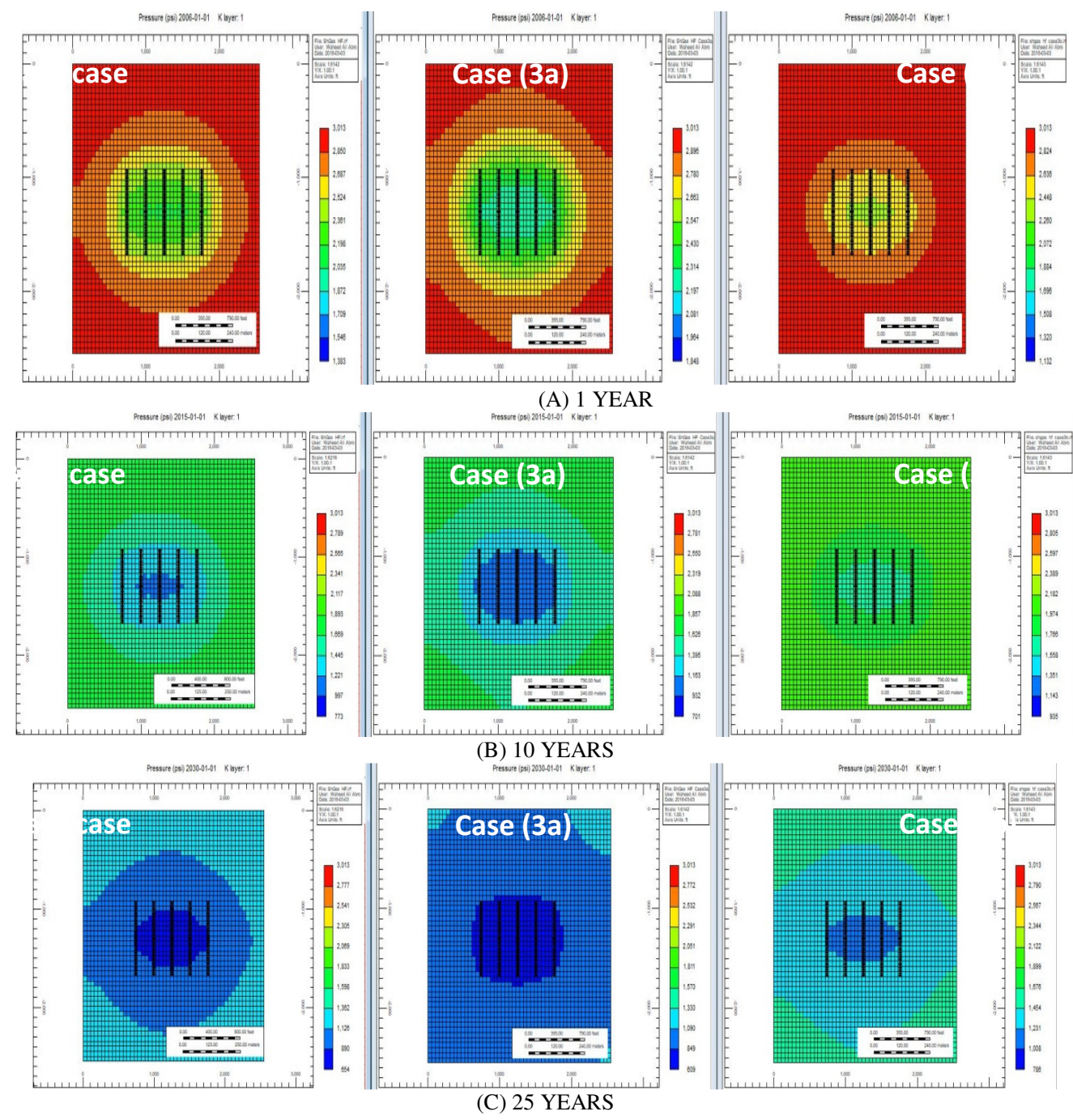

FIG. 7. COMPARISON OF PRESSURES AT DRAINAGE BOUNDARY AT DIFFERENT TIME PERIODS

other two cases of fracture conductivity is quiet significant. The conductivity of fracture is increased the production rate and gas production cumulative increase and vice versa as shown in Fig. 6. Hence, from this study simulation results, it is found that fracture conductivity with $20 \mathrm{md}-\mathrm{ft}$ (Case-3a) has large production. The impact of these fracture conductivities on pressure is also shown at different time periods in Fig. 7.

\subsubsection{Effect of Permeability Heterogeneity}

Permeability heterogeneity plays a significant role on productivity of shale gas reservoirs. In this study we performed simulation by considering the two different reservoir heterogeneity cases of (Case-4a) moderate and (Case-4b) severe heterogeneity effects. This modelling approach can provide a better representation of the reservoir properties variations effect on shale gas production performance. Most of the reservoirs are heterogeneous in nature, the two different case of heterogeneity studies in present study are shown in Fig. 9. Impact of reservoir heterogeneities on shale gas reservoir cumulative production and gas rate was compared analyzed, the results obtained are presented in Fig. 8. From simulation results it is found that the more the reservoir is heterogeneous less is the recovery and rate. The cumulative production trend line for medium and severe heterogeneity compared with the base case model are lower and the moderate heterogeneity on some extent is closer to base case model compared to 

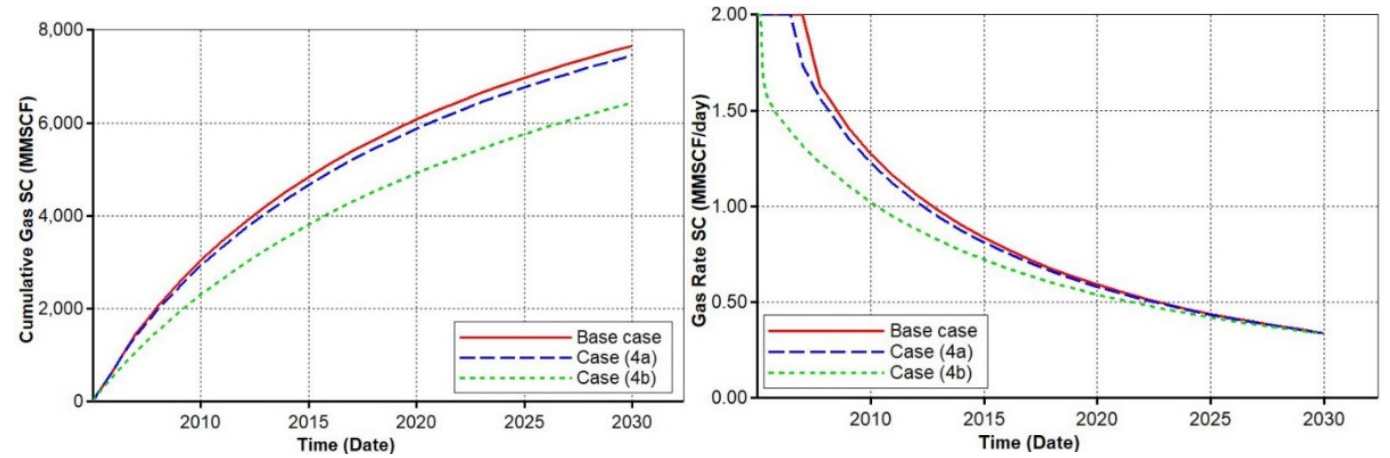

FIG. 8. EFFECT OF RESERVOIR HETEROGENEITY ON GAS PRODUCTION RATE AND CUMULATIVE GAS PRODUCTION

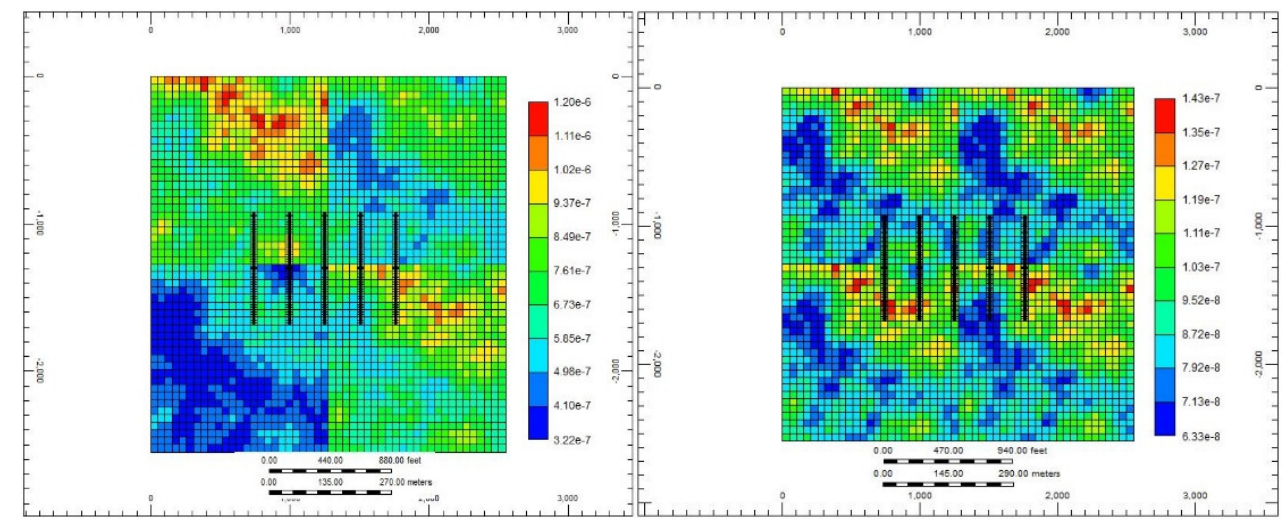

FIG. 9. ILLUSTRATION SHOWS THE EFFECT OF TWO PERMEABILITY HETROGEITY CASES (4A) MODERATE HETROGENITY CASE (4B)SEVERE HETROGENITY

severe heterogeneous model. Hence, the permeability heterogeneity plays a significant impact on gas rate and cumulative gas production for shale gas reservoirs and the effect must be taken into account.

\section{CONCLUSION}

In this research study, we attempted to analyze the impact of various parameters on the productivity of heterogeneous shale gas reservoirs leading to the following conclusions.

(i) A synthetic reservoir simulation model of shale gas reservoir considering dual porosity and dual permeability of naturally fractured reservoir with multistage hydraulic fracturing with single horizontal well was constructed. This method of modelling the shale gas reservoir is suitable to predict the productivity of heterogeneous shale gas reservoirs penetrating the horizontal well with non-uniform fracture configurations. (ii) Prior to sensitivity analysis model was validated with the field data taken from Barnet shale original data, which is present within the public domain. Then a synthetic reservoir model was constructed with hydraulic fractures for shale gas reservoirs performance analysis.

(iii) The influence of fracture half-length was significant as it was expected that there is a large effects of fracture half-length on the production.

(iv) From sensitivity analysis it was found that the severely heterogonous reservoirs significantly effects on the productivity of shale gas reservoir. Moreover, the effect of fracture spacing was less significant than the fracture half-length while the conductivity of fractures was more dominant in affecting the shale gas reservoir productivity.

\section{ACKNOWLEDGMENTS}

The author would like to express the sincere gratitude to NED University of Engineering \& Technology, 
Karachi, and Mehran University of Engineering \& Technology, Jamshoro, Pakistan, for providing conducive environment to conduct this research study. Authors also greatly acknowledge the CMG stars computer Modelling Group for providing software license for the study.

\section{REFERENCES}

[1] Shar, A.M., Mahesar, A.A., and Memon, K.R., "Could Shale Gas Meet Energy Deficit: Its Current Status and Future Prospects", Journal of Petroleum Exploration and Production Technology, Vol. 8, No. 4, pp, 957-967, 2017.

[2] Energy Information Administration (EIA). Annual Energy Outlook. U.S. Energy Information Administration. 2016.

[3] Kok, M.V., and Merey, S., "Shale Gas: Current Perspectives and Future Prospects in Turkey and The World" Energy Sources, Part A: Recovery, Utilization, and Environmental Effects, Vol. 36, No. 22, pp, 2492-2501, 2014.

[4] Cipolla, C.L., Williams, M.J., Weng, X., Mack, M., and Maxwell, S., "Hydraulic Fracture Monitoring to Reservoir Simulation: Maximizing Value" SPE Annual Technical Conference and Exhibition, Vol. 2, pp, 13771402, 2010.

[5] Guo, C., Wei, M., and Liu, H., "Modeling of Gas Production from Shale Reservoirs Considering Multiple Transport Mechanisms" PLoS ONE Vol. 10, No. 12, pp, 1-24 2015.

[6] Yu, W., Luo, Z., Javadpour, F., Varavei, A., and Sepehrnoori, K., "Sensitivity Analysis of Hydraulic Fracture Geometry in Shale" Journal of Petroleum Science and Engineering, Vol. 113, pp, 1-7, 2014.

[7] Fazelipour, W., "Innovative Reservoir Modeling and Simulation of Unconventional Shale Gas Reservoirs Powered by Microseismic Data", Society of Petroleum Engineers Middle East Unconventional Gas Conference and Exhibition, 2011.

[8] Ozkan, E., Raghavan, R.S., and Apaydin, O.G., "Modeling of Fluid Transfer From
Shale Matrix to Fracture Network", Society of Petroleum Engineers Annual technical conference and exhibition, 2010.

[9] Rubin, B., "Accurate Simulation of NonDarcy Flow in Stimulated Fractured Shale Reservoirs", SPE Western regional meeting, Society of Petroleum Engineers, 2010.

[10] Jahandideh, A., and Jafarpour, B., "Optimization of Hydraulic Fracturing Design under Spatially Variable Shale Fracability", Journal of Petroleum Science and Engineering, Vol. 138, pp, 174-188, 2016.

[11] Faybishenko, B., Witherspoon, P.A., and Benson, S.M., "Dynamics of Fluids in Fractured Rock", Geophys. Monogr. Ser., Vol., 122, 2000.

[12] Kazemi, H., "Pressure Transient Analysis of Naturally Fractured Reservoirs with Uniform Fracture Distribution", Society of Petroleum Engineers Journal, Vol. 9, No 4, pp, 451-462, 1969.

[13] Warren, J. E., and Root, P. J., "The Behavior of Naturally Fractured Reservoirs", Society of Petroleum Engineers Journal, Vol. 3, No 3, pp, 245-255, 1963.

[14] Pruess, K., "A Practical Method for Modeling Fluid and Heat Flow in Fractured Porous Media", Society of Petroleum Engineers Journal, Vol. 25, No 1, pp, 14-26, 1985.

[15] Dershowitz, W.S., LaPointe, P.R., and Doe, T.W., "Advances in Discrete Fracture Network Modelling", Proceedings of the US EPA/NGWA fractured rock conference, Portland, pp, 882-894, 2004.

[16] Civan, F., Chandra, S.R., and Carl, H. S., "Shale-Gas Permeability and Diffusivity Inferred by Improved Formulation Of Relevant Retention And Transport Mechanisms" Transport in Porous Media, Vol. 86, No. 3, pp, 925-944, 2011.

[17] Moridis, George J., Thomas Alwin Blasingame, and Craig Matt Freeman. "Analysis of Mechanisms of Flow in Fractured Tight-Gas and Shale-Gas Reservoirs", Society of Petroleum Engineers, 
Latin American and Caribbean Petroleum Engineering Conference, Feburary, 2010.

Wu, Y.S., "Effective Continuum Method for Modelling Multiphase Flow, Multicomponent Transport, and Heat Transfer In Fractured Rock, in Dynamics of Fluids in Fractured Rock" Geophysical Monograph Series, pp, 299-312, 2000.

[19] Bustin, R. M., Bustin, A. M., Cui, A., Ross, D., and Pathi, V. M., "Impact of Shale Properties on Pore Structure and Storage Characteristics", Society of Petroleum Engineers shale gas production conference, January , 2008.

[20] Grieser, W.V., Shelley, R.F., Soliman, M.Y. "Predicting production outcome from multistage, horizontal Barnett completions". SPE Production and Operations Symposium, 4-8 April, Oklahoma City, Oklahoma. SPE120271. Pp, 1245, 140, 2009.

[21] Cipolla, C.L., Maxwell, S.C., Mack, M.G., "Engineering Guide to the Application of Microseismic Interpretations" Society of Petroleum Engineers SPE Hydraulic Fracturing Technology Conference, January ,2012.

[22] Cipolla, C.L., Fitzpatrick, T., Williams, M.J., and Ganguly U.K., "Seismic-to-Simulation for Unconventional Reservoir Development", Society of Petroleum Engineers Reservoir Characterisation and Simulation Conference and Exhibition, September, 2011.

[23] Warpinski, N., Kramm, R.C., Heinze, J.R., and Waltman, C.K., "Comparison of Singleand Dual-Array Microseismic Mapping Techniques in the Barnett Shale", Society of Petroleum Engineers Annual Technical Conference and Exhibition, August, 2005.

[24] Weng, X., Kresse, O., Cohen, C.E., Wu, R., and $\mathrm{Gu}, \mathrm{H}$., "Modeling of HydraulicFracture-Network Propagation in a Naturally Fractured Formation", SPE Production \& Operations, Vol. 26, No, 04, pp, 368-80, 2011.
[25] Mirzaei, M., and Cipolla, C.L., "A Workflow for Modeling and Simulation of Hydraulic Fractures in Unconventional Gas Reservoirs" SPE Middle East Unconventional Gas Conference and Exhibition, Society of Petroleum Engineers, 2012.

[26] Olson, J.E, and Wu, K., "Sequential vs. Simultaneous Multizone Fracturing in Horizontal Wells: Insights From a NonPlanar, Multifrac Numerical Model, Society of Petroleum Engineers Hydraulic Fracturing Technology Conference, , 2012.

[27] Moinfar, A., Varavei A., Sapehrooni, K., and Johns, R., "Development of an Efficient Embedded Discrete Fracture Model for 3D Compositional Reservoir Simulation in Fractured Reservoirs" SPE Journal, Vol. 19, No. 2, pp, 289-303, 2013.

[28] Yu, W., and Sepehrnoori, K., "Optimization of Multiple Hydraulically Fractured Horizontal Wells in Unconventional Gas Reservoirs", Journal of Petroleum Engineering, Volume 2013, pp, 1-16, 2013.

[29] Weng, X., "Modeling of Complex Hydraulic Fractures in Naturally Fractured Formation", Journal of Unconventional Oil and Gas Resources, Vol. 9, pp, 114-35.

[30] Memon, K.R., Tunio, A., Mahesar, A. and Baladi, S.A.,." Laboratory Investigation to Assess the Impact of Pore Pressure Decline and Confining Stress on Shale Gas Reservoirs", Mehran University Research Journal of Engineering and Technology, Vol. 37(1), pp.159-168, 2018. 